\title{
In search of the smoking gun in calcific aortic valve disease
}

\author{
Takashi Murashita, MD, and Vinay Badhwar, MD
}

\author{
From the Department of Cardiovascular and Thoracic Surgery, West Virginia University, Morgantown, WVa. \\ Disclosures: Authors have nothing to disclose with regard to commercial support. \\ Received for publication Feb 12, 2017; accepted for publication Feb 15, 2017; available ahead of print March 24, \\ 2017. \\ Address for reprints: Vinay Badhwar, MD, Department of Cardiovascular and Thoracic Surgery, West Virginia \\ University, 1 Medical Center Drive, Morgantown, WV 26506 (E-mail: vinay.badhwar@wvumedicine.org). \\ J Thorac Cardiovasc Surg 2017;153:1328-9 \\ $0022-5223 / \$ 36.00$ \\ Copyright $\subset 2017$ by The American Association for Thoracic Surgery \\ http://dx.doi.org/10.1016/j.jtcvs.2017.02.039
}

In this issue of the Journal, $\mathrm{Li}$ and colleagues ${ }^{1}$ report their observations on a macrophage-mediated inflammatory mechanism in calcific aortic valve disease (CAVD). They studied valvular interstitial cells from 60 calcified trileaflet valves harvested at the time of aortic valve replacement and 30 noncalcified control aortic valves harvested at heart transplantation and subjected these to an elegant cellular analysis. They determined that the proinflammatory M1 macrophage elicits a tumor necrosis factor- $\alpha$ and interleukin-6-mediated osteogenic differentiation of valvular interstitial cells. In other words, this study provides further corroborative evidence to support an inflammatory mechanism to calcific aortic stenosis and suggests a possible mechanism as to how this may occur.

For over a decade, the pathoetiology of CAVD has been identified to be not only merely degenerative but also inflammatory. It is now understood that CAVD progression involves the combination of genetic predisposition, endothelial dysfunction, lipoprotein retention and signaling, oxidative stress, inflammation, and renin-angiotensin system activation. ${ }^{2}$ Similar to atherosclerosis, the pathogenesis of CAVD is reported to be lipid mediated, yet earlier studies have found that statin therapy did not have a substantive clinical impact on mitigating the progression of aortic stenosis. ${ }^{3,4}$ Statins inhibit 3-hydroxy-3-methylglutaryl coenzyme A reductase to reduce low-density lipoproteins. However, the atherogenic component of CAVD may be more accurately related to phospholipid oxidization secondary to the proinflammatory effects of lipoprotein(a). ${ }^{5}$ This response to lipoprotein(a) often may have a genetic component that crosses multiple racial groups and follows a pathway to CAVD that is not altered by lifestyle modification. ${ }^{6}$

In the current study, $\mathrm{Li}$ and colleagues ${ }^{1}$ surmised that the secretory properties of M1 macrophages to exude tumor necrosis factor- $\alpha$ and interleukin- 6 could be truncated by antibodies to these cytokines. Perhaps this is but one mechanism in the proinflammatory cascade associated with CAVD. Further work in this area could identify specific pharmacologic targets to mitigate aortic calcification. trials.

\section{References} 153:1318-27.e1.

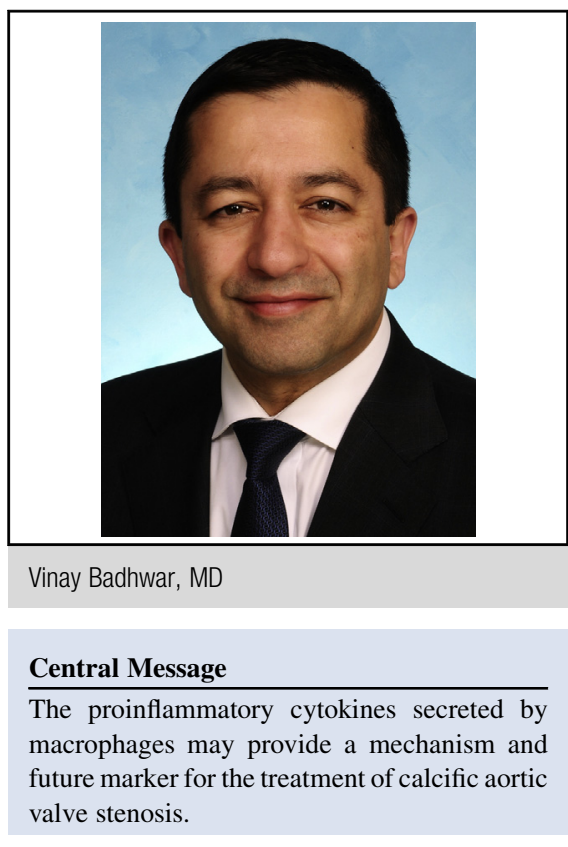

See Article page 1318 .

Solutions may not be that far off after all. Lipoprotein(a) is known to be subject to reduction by proprotein convertase subtilisn/kexin type 9 inhibitors that are now pharmacologically available. Furthermore, the most sensitive current way to address the inflammatory properties of lipoprotein(a) is through antisense oligonucleotides. There is currently a clinical trial under way to explore the impact of these antibodies on modulating CAVD. ${ }^{7}$ Like lipoprotein(a), perhaps the cytokine-mediated proinflammatory effects of the M1 macrophages could be blunted by this form of targeted treatment. Although the current study ${ }^{1}$ may not provide us with the smoking gun for CAVD, it may provide an outcome marker or even a therapeutic target for future

1. Li G, Qiao W, Zhang W, Li F, Shi J, Dong N. The shift of macrophages toward M1 phenotype promotes aortic valvular calcification. J Thorac Cardiovasc Surg. 2017;

2. Rajamannan NM, Evans FJ, Aikawa E, Grande-Allen KJ, Demer LL, Heistad DD, et al. Calcific aortic valve disease: not simply a degenerative process: a review and agenda for research from the National Heart and Lung and Blood Institute Aortic Stenosis Working Group. Executive summary: Calcific aortic valve disease-2011 update. Circulation. 2011;124:1783-91.

3. Chan KL, Teo K, Dumesnil JG, Ni A, Tam J, ASTRONOMER Investigators. Effect of Lipid lowering with rosuvastatin on progression of aortic stenosis: results of the aortic stenosis progression observation: measuring effects of rosuvastatin (ASTRONOMER) trial. Circulation. 2010;121:306-14. 
4. Zhao Y, Nicoll R, He YH, Henein MY. The effect of statins on valve function and calcification in aortic stenosis: a meta-analysis. Atherosclerosis. 2016;246: 318-24.

5. Capoulade R, Chan KL, Yeang C, Mathieu P, Bossé Y, Dumesnil JG, et al. Oxidized phospholipids, lipoprotein(a), and progression of calcific aortic valve stenosis. J Am Coll Cardiol. 2015;66:1236-46.
6. Tsimikas S. A test in context: Lipoprotein(a): diagnosis, prognosis, controversies, and emerging therapies. J Am Coll Cardiol. 2017;69:692-711.

7. Viney NJ, van Capelleveen JC, Geary RS, Xia S, Tami JA, Yu RZ, et al. Antisense oligonucleotides targeting apolipoprotein(a) in people with raised lipoprotein(a): two randomised double-blind placebo-controlled dose-ranging trials. Lancet. 2016;388:2239-53 